\title{
AMPK is indispensable for overload- induced muscle glucose uptake and glycogenesis but dispensable for inducing hypertrophy in mice
}

\section{$\operatorname{AUTHOR}(S):$}

Kido, Kohei; Egawa, Tatsuro; Fujiyoshi, Haruna;

Suzuki, Hikari; Kawanaka, Kentaro; Hayashi, Tatsuya

\section{CITATION:}

Kido, Kohei ...[et al]. AMPK is indispensable for overload-induced muscle glucose uptake and glycogenesis but dispensable for inducing hypertrophy in mice. FASEB journal : official publication of the Federation of American Societies for Experimental Biology 2021, 35(4): e21459.

\section{ISSUE DATE:}

2021-04

URL:

http://hdl.handle.net/2433/266462

\section{RIGHT:}

This is the original submitted manuscript of following article: 'FASEB Journal' Volume35, Issue4, e21459, https://doi.org/10.1096/fj.202002164R.; This is not the published version. Please cite only the published version. この論文は出版社版でありません。引用の際には 出版社版をご確認ご利用ください。 
AMPK is indispensable for overload-induced muscle glucose uptake and glycogenesis but dispensable for inducing hypertrophy in mice

Running title: Regulations by AMPK/GLUT4 and HKII axes

Kohei Kido ${ }^{1,2,3^{* \#}}$, Tatsuro Egawa ${ }^{1 \#}$, Hikari Suzuki ${ }^{1}$, Tatsuya Hayashi ${ }^{1}$

${ }^{1}$ Laboratory of Sports and Exercise Medicine, Graduate School of Human and Environmental Studies, Kyoto University, Kyoto, Japan.

${ }^{2}$ Faculty of Sports and Health Science, Fukuoka University, Fukuoka, Japan.

${ }^{3}$ Institute for Physical Activity, Fukuoka University.

*Corresponding Author: Kohei Kido, Laboratory of Sports and Exercise Medicine, Graduate School of Human and Environmental Studies, Yoshida-nihonmatsu-cho, Sakyo-ku, Kyoto 606-8501, Japan.

E-mail: kohei.kido110@gmail.com

Phone no: $+81-75-753-6640$

Fax No.: +81-75-753-6640

\#Equal Contributing Authors: Kohei Kido and Tatsuro Egawa contributed equally to this study. 


\section{Nonstandard Abbreviations}

AMPK: AMP-activated protein kinase

AMPK-DN: dominant-negative mutant of AMPK

GLUT1: glucose transporter 1

GLUT4: glucose transporter 4

GS: glycogen synthase

GSK-3 $\beta$ : glycogen synthase kinase-3 $\beta$

HbA1c: haemoglobin A1c

HKI: hexokinase I

HKII: hexokinase II

KO: knockout

MHC: myosin heavy chain

WT: wild type

\section{Acknowledgement}

We are grateful to Kyoto University Radioisotope Research Centre for their support.

\section{Conflict of Interest}

The authors declare no conflicts of interest.

\section{Author Contributions}

K.K. conceived and designed the study; K.K., T.E., and H.S. performed the experiments; K.K. analysed the data; K.K., T.E., H.S., and T.H. interpreted the results; K.K. prepared the figures; K.K. drafted manuscript; all authors approved the final version of the manuscript. 


\section{Abstract}

Chronic muscle loading (overload) induces the skeletal muscles to undergo hypertrophy and an increased glucose uptake. AMPK reportedly serves as a negative regulator of hypertrophy and a positive regulator of glucose uptake. However, the role of AMPK in overload-induced skeletal muscle hypertrophy as well as glucose uptake is not clear. This study aimed to determine whether AMPK regulates overload-induced hypertrophy and glucose uptake in the skeletal muscles. The skeletal muscle overload was induced through unilateral synergist ablations in the wild type (WT) and transgenic mice, expressing the dominant-negative mutation of AMPK (AMPK-DN). After two weeks, the parameters, such as muscle weight, glycogen, and in vivo $\left[{ }^{3} \mathrm{H}\right]$-2-deoxy-D-glucose uptake, were assessed. As results, there was no significant difference in the body weight and blood glucose level between the WT and AMPK-DN mice. The two-week muscle overload activated the AMPK pathway in the skeletal muscle of the WT mice; however, the response was impaired in the AMPK DN mice. Despite a normal gain in muscle mass, the AMPK-DN mice demonstrated a significant impairment of overload-induced muscle glucose uptake and glycogenesis, compared to the WT mice. Overload-induced the change in GLUT4 and HKII expression levels were lowered in the AMPK-DN mice, compared to those in the WT mice. This study demonstrated that AMPK activation is indispensable for overload-induced muscle glucose uptake and glycogenesis but dispensable for inducing hypertrophy in the AMPK-DN mice. It also substantiated that the AMPK/GLUT4 and HKII axes regulate overload-induced muscle glucose uptake and glycogenesis. 


\section{Keywords}

AMPK, functional-overload, glucose uptake, hypertrophy, skeletal muscle 


\section{Introduction}

Increase in physical activity is one of the factors that reduce the incidence of type 2 diabetes (T2D). ${ }^{1}$ Chronic exercise training, which includes both aerobic and resistance training have been recommended for preventing and improving T2D. Resistance training has been particularly demonstrated to reduce the haemoglobin, A1c $(\mathrm{HbA} 1 \mathrm{c}),{ }^{2}$ increasing the disposal of whole-body glucose. ${ }^{3}$ Resistance exercise training causes an increase in both muscle mass and glucose uptake per muscle weight. ${ }^{4}$ Therefore, resistance training is a powerful physiological stimulus for enhancing whole-muscle glucose uptake. Skeletal muscles account for approximately $40 \%$ of the total human body weight and play key roles in determining the whole-body glucose metabolism. ${ }^{5}$ This necessitates understanding the regulatory mechanism of glucose metabolism in the skeletal muscles, for treating diabetes.

Resistance training is a well-established exercise method inducing skeletal muscle hypertrophy in humans. The functional overload that is induced by the ablation of synergist muscles mimics the resistance exercises in rodents. ${ }^{6,7}$ Overload induces muscle hypertrophy and increases the glucose uptake per muscle weight, at rest. ${ }^{6-8}$ Therefore, it is one of the best tools for identifying the regulatory mechanism of muscles through resistance training.

AMP-activated protein kinase (AMPK) is a key regulator of glucose metabolism in muscles; therefore, it is also considered as a therapeutic target for T2D. ${ }^{9}$ Previous studies have demonstrated that AMPK regulates aerobic training-induced metabolic adaptations in the skeletal muscles, including glucose metabolism and 
expression of the regulatory proteins. ${ }^{10,11}$ Resistance training also activates AMPK in humans as well as rodents, ${ }^{12-14}$ and functional overload leads to the chronic activation of AMPK. ${ }^{6}$ However, the mechanism through which the muscle glucose uptake is regulated by AMPK during resistance training/overload effect is not clear. AMPK activation has been reported to increase the expression of the genes of key glucose-handling intermediates, glucose transporter 4 (GLUT4) and hexokinase II (HKII). ${ }^{15,16}$ Moreover, chronic aerobic training increases the expression of HKII and mitochondrial proteins. However, these responses were disrupted in the muscles of AMPK $\alpha$ knockout $(\mathrm{KO})$ mice. ${ }^{11}$ Resistance training has shown an increase in GLUT4 and HKII in the muscles. ${ }^{17,18}$ Thus, the AMPK/GLUT4 and HKII axis may control the increase in glucose uptake due to the overload.

It has been believed that AMPK activation inhibits protein synthesis and hypertrophy in muscles. Indeed, pharmacological AMPK activation inhibits muscle growth both in vitro and in vivo. ${ }^{19,20}$ Mounier et al. suggested that the knockout of AMPK $\alpha 1 / \alpha 2$ and the whole-body AMPK $\alpha 1$ in the skeletal muscles increase the basal muscle mass as well as the response to overload-induced muscle hypertrophy, respectively. ${ }^{20,21}$ In contrast, some studies indicate that neither the KO of AMPK 22 upstream kinase, LKB1 nor the AMPK $\gamma 3$ KO affects overload-induced muscle hypertrophy. ${ }^{6,22}$ Besides, the inducible AMPKa1/a2 KO in the mice did not induce muscle hypertrophy. ${ }^{10}$ Thus, the relationship between the function of AMPK and regulation of muscle mass in vivo is controversial.

Based upon the reported roles of AMPK in overload-induced muscle glucose 
uptake and growth, the effects of functional overload on glucose metabolism and muscle growth were studied in the transgenic mice expressing the dominant-negative mutation of AMPK (AMPK-DN).

\section{Materials and Methods}

\section{Animals}

The transgenic (AMPK-DN) mice expressing a dominant-negative mutation of AMPK $\alpha 1$ in the skeletal muscles ${ }^{23}$ were obtained from the JCRB (Japanese Collection of Research Bioresources Cell Bank) Laboratory Animal Resource Bank at the National Institute of Biomedical Innovation (Osaka, Japan). The heterozygous AMPK-DN mice were backcrossed with the C57BL/6NCr mice, and 14 male AMPK-DN mice (age 16.8 $\pm 1.7 \mathrm{wk}$; mean \pm SEM) and 12 male wild types (WT) mice (age $15.9 \pm 1.4 \mathrm{wk}$; mean \pm SEM) were selected. All the mice were housed in an animal room maintained at $22-$ $24{ }^{\circ} \mathrm{C}$ with a $12: 12 \mathrm{~h}$ light-dark cycle and fed a standard laboratory diet and water $\mathrm{ad}$ libitum. All the protocols involving animals were carried out in accordance with the guidelines for the care and use of laboratory animals by the National Institutes of Health (Bethesda, MD, USA). The animal studies were approved by the Kyoto University Graduate School of Human and Environmental Studies (approval number: 19-A-2) and Kyoto University Radioisotope Research Centre (approval number: 19-9). All the animals were treated under anaesthesia induced by intraperitoneal injections of sodium pentobarbital (5 or $10 \mathrm{mg} / 100 \mathrm{~g}$ body weight). 


\section{Functional overload}

Functional overload was induced by the surgical bilateral ablation of the soleus and gastrocnemius muscles. ${ }^{24,25}$ Mice were anaesthetized with sodium pentobarbital (5 $\mathrm{mg} / 100 \mathrm{~g}$ body weight), and the skin on the back of the right leg was opened from the ankle to the popliteal. Using forceps and scissors, the soleus and gastrocnemius muscles were dissected out and the skin of the right leg was sutured back together. The left leg was subjected to sham-operation where the skin was opened similar to that in the right leg, and the plantaris, soleus, and gastrocnemius muscles were gently separated from each other. Subsequently, the opened skin layers were sutured. Two weeks after the surgery, the plantaris muscle in the operated mice was used for either muscle 2-deoxy-glucose uptake measurement or biochemical analyses.

\section{Western blot analysis}

The muscle samples for Western blotting were prepared as described previously ${ }^{26}$ with some modifications. Frozen muscles were homogenized in ice-cold buffer $(1: 40 \mathrm{wt} / \mathrm{vol})$ containing $20 \mathrm{mmol} / \mathrm{L}$ Tris. $\mathrm{HCl}(\mathrm{pH} 7.4), 1 \%$ Triton X-100, 50 $\mathrm{mmol} / \mathrm{L} \mathrm{NaCl}, 250 \mathrm{mmol} / \mathrm{L}$ sucrose, $50 \mathrm{mmol} / \mathrm{L} \mathrm{NaF}, 5 \mathrm{mmol} / \mathrm{L}$ sodium pyrophosphate, 2 $\mathrm{mmol} / \mathrm{L}$ dithiothreitol, $4 \mathrm{mg} / \mathrm{L}$ leupeptin, $50 \mathrm{mg} / \mathrm{L}$ trypsin inhibitor, $0.1 \mathrm{mmol} / \mathrm{L}$ benzamidine, $1 \mathrm{mmol} / \mathrm{L} \mathrm{Na}_{3} \mathrm{VO}_{4}$, and $0.5 \mathrm{mmol} / \mathrm{L}$ phenylmethylsulfonyl fluoride, and centrifuged at $16,000 \mathrm{~g}$ for $30 \mathrm{~min}$ at $4^{\circ} \mathrm{C}$. The supernatants were collected to determine the protein content using the Bradford technique (Protein Assay CBB, Nacalai Tesque, Kyoto, Japan). The supernatants were then solubilized in Laemmli sample buffer and 
boiled for $5 \mathrm{~min}$. A part of non-boiled Laemmli samples were stored and used for glucose transporter 1 (GLUT1) and GLUT4 detection. Either boiled or non-boiled samples (10 $\mu \mathrm{g}$ of protein) were separated by sodium dodecyl sulfate-polyacrylamide gel electrophoresis (SDS-PAGE) using 7.5\% polyacrylamide gel. After SDS-PAGE, the proteins were transferred to polyvinylidene difluoride (PVDF) membranes (Millipore, MA, USA) using Trans-Blot cell (Bio-Rad Laboratories) at $4^{\circ} \mathrm{C}$. Next, the membranes were blocked for $30 \mathrm{~min}$ using $3 \%$ fat-free skim milk with Tris-buffered saline containing $0.1 \%$ Tween 20 (TBS-T; pH 7.5). The membranes were then incubated overnight at $4{ }^{\circ} \mathrm{C}$ with primary antibodies against total AMPK $\alpha$ (t-AMPK $\left.\alpha\right)(1: 2000$, Cat\#5832), total ACC (t-ACC) (1:1000, Cat \#3662), phosphospecific Akt (p-Akt)-Thr ${ }^{308}\left(1: 1000\right.$, Cat \#13038), p-Akt- $\operatorname{Ser}^{473}$ (1:2000, Cat \#9271), total Akt (t-Akt) (1:1000, Cat \#9272), phosphospecific glycogen synthase kinase-3 $\beta-\operatorname{Ser}^{9}$ (p-GSK-3 $\beta$ -Ser $\left.{ }^{9}\right)(1: 1000$, Cat \#9336), total GSK-3 $\beta$ (t-GSK-3 $\beta$ ) (1:1000, Cat \#9336), phosphospecific glycogen synthase-Ser ${ }^{641}\left(\mathrm{p}-\mathrm{GS}-\mathrm{Ser}^{641}\right)(1: 1000$, Cat \#3891), total GS (t-GS) (1:1000, Cat \#3893), total TBC1D1 (t-TBC1D1) (1:1000, Cat\#5929), phosphospecific TBC1D4-Thr ${ }^{649}$ (1:1000, p-TBC1D1-Thr $\left.{ }^{649}\right)$ (1:2000, Cat \#4288), p-TBC1D4-Ser ${ }^{595}$ (1:1000, Cat \#8730), total TBC1D4 (t-TBC1D4) (1:1000, Cat \#2670), glucose transporter 1 (GLUT1) (1:1000, Cat \#12939), hexokinase I (HKI) (1:1000, Cat \#2024), and HKII (1:1000, Cat \#2867) (Cell Signaling Technologies, MA, USA); phosphospecific ACC (p-ACC)-Ser ${ }^{79}\left(\operatorname{Ser}^{212}\right)$ (1:1000, Cat \#2694476), phosphospecific TBC1D1-Ser ${ }^{231}$ (p-TBC1D1-Ser ${ }^{231}$ ) (1:1000, Cat\#2273986) (Millipore, Billerica, MA, USA); GLUT4 (1:1000, Cat \#4670-1704; Bio-Rad Laboratories, Inc., CA, USA); and 
PGC-1 $\alpha$ (1:1000, Cat \#13067; Santa Cruz Biotechnology, TX, USA). The probed membranes were washed with TBS-T and reacted with the appropriate secondary antibodies (Cell Signaling Technology, MA, USA) for $1 \mathrm{~h}$ at room temperature. After a final wash with TBS-T, the protein bands were visualized using ImmunoStar LD (Wako, Osaka, Japan). The signal density was measured using a WSE-6100 LuminoGraph (ATTO, Tokyo, Japan). Densitometry was performed using Image Lab ${ }^{\mathrm{TM}}$ software (Bio-Rad Laboratories, Inc., CA, USA).

\section{In vivo glucose uptake}

The glucose uptake was measured as previously described. ${ }^{27}$ Briefly, the tail blood was collected from the $2 \mathrm{~h}$-fasted mice at time points 0,5 , and $10 \mathrm{~min}$. After the first blood sample was drawn, a bolus of $\left[{ }^{3} \mathrm{H}\right]-2$-deoxyglucose $(12.3 \mathrm{MBq} / \mathrm{kg}$ body weight) dissolved in isotonic saline was injected retro-orbitally. After the last blood samples were drawn, the plantaris muscles were rapidly dissected and frozen in liquid nitrogen. The $\left[{ }^{3} \mathrm{H}\right]$-2-deoxyglucose uptake in the muscles was assessed based upon the accumulated $\left[{ }^{3} \mathrm{H}\right]$-2-deoxyglucose-6-phosphate and the tracer-specific activity in the plasma.

\section{Muscle Glycogen measurement}

The glycogen content in the muscle was measured using a glucose assay reagent (Glucose CII Test, Wako, Osaka, Japan) as described previously. ${ }^{28}$ 


\section{Myosin heavy chain (MHC) isoform detection}

Analyses of the MHC isoform (I, IIa, IIx, and IIb) levels were performed as previously described. ${ }^{29}$ Briefly, the homogenate sample proteins $(5 \mu \mathrm{g})$ were separated by the SDS-PAGE using a $8 \%$ polyacrylamide gel at $120 \mathrm{~V}$ for $19 \mathrm{~h}$ in a temperature-controlled chamber at $4{ }^{\circ} \mathrm{C}$. After electrophoresis, the gels were stained using the Oriole ${ }^{\mathrm{TM}}$ Fluorescent Gel Stain (Bio-Rad Laboratories, CA, USA). The gels were visualized using a WSE-6100 LuminoGraph (ATTO, Tokyo, Japan) and analysed using the Image $\mathrm{Lab}^{\mathrm{TM}}$ software (Bio-Rad Laboratories, Inc., California, United States).

\section{Statistical analyses}

Data are presented as means \pm SEM. Two-way ANOVA with repeated measures and unpaired Student's t tests were used to assess statistical significance within and between interventions, where appropriate. Post hoc analysis was performed using Bonferroni-Sidak test, when appropriate. Main effects have been indicated by lines. Statistical significance was defined as $P<0.05$.

\section{Results}

\section{AMPK signalling activation in the plantaris of the AMPK-DN mice}

The total AMPK $\alpha$ was found to highly express in the AMPK-DN mice, which reflected the overexpression of the dominant-negative mutation of AMPK $\alpha 1$ (Fig.1A). The phosphorylation of the downstream target of AMPK, ACC at $\operatorname{Ser}^{79}$ was significantly increased due to the overload; however, the increase in p-ACC $\operatorname{Ser}^{79}$ was significantly 
lower in the AMPK-DN mice compared to that in the WT mice (Fig. 1C). The total ACC expression was significantly higher in the AMPK-DN mice (Fig. 1B). In addition to this, we have previously indicated that AMPK-DN mice show significantly low AMPK $\alpha 1$ and AMPK $\alpha 2$ activities. ${ }^{29,30}$

The level of another downstream target of AMPK, p-TBC1D1 Ser ${ }^{231}$ was increased due to the overload in the WT but not in the AMPK-DN mice. The phosphorylation levels in both the sham and overloaded muscles were significantly lower in the AMPK-DN mice compared to those in the WT mice (Fig. 1E). Neither overload nor genotype could affect the level of t-TBC1D1 (Fig. 1D).

\section{AMPK-DN does not affect overload-induced muscle hypertrophy}

The plantaris muscle mass was significantly increased due to the overload both in the WT as well as AMPK-DN mice (Fig. 2B-C). Moreover, the bodyweight of the AMPK-DN mice was not different from WT mice (Fig. 2A). In contrast, the functional overload in the AMPK-DN mice significantly increased and decreased the percentages of MHC type IIa/x and IIb, respectively (Fig. 2E-F). These responses were significantly lower in the WT compared to the AMPK-DN mice (Fig. 2E-F). The percentage of MHC type I was unaffected by both the overload as well as AMPK-DN (Fig. 2D). 
Overload-induced muscle glucose uptake and glycogenesis are impaired in the AMPK-DN mice

To determine whether AMPK regulates overload-induced glucose uptake by the skeletal muscle, a bolus of $\left[{ }^{3} \mathrm{H}\right]$-2-deoxyglucose was injected retro-orbitally both in the WT and AMPK-DN mice. The overload significantly increased the glucose uptake in the plantaris muscles of both the WT and AMPK-DN mice. However, the delta increase in the AMPK-DN mice was significantly lower than in the WT mice (Fig. 3BC). Moreover, the skeletal muscle glycogen content was significantly increased by overload in WT mice but not in AMPK-DN mice, and the delta increase was significantly lower in AMPK-DN mice than the WT mice (Fig. 3E-F). The differences in the blood glucose levels were different between the genotypes (Fig. 3A).

\section{AMPK-DN impairs the adaptations of glucose-handling intermediates during the} overload

To find out the factors mediating the lowered glucose uptake in the AMPK-DN mice, the expression of glucose handling intermediates was determined. The expression of HKI and GLUT1 were significantly increased and decreased, respectively (Fig. 4C and G), in both the WT as well as AMPK-DN mice due to the overload (Fig. 4D and H). However, muscles of the AMPK-DN mice depressed levels of GLUT1 compared to the WT mice (Fig. 4G). Additionally, the HKII and GLUT4 delta increase due to the overload were significantly lower in the AMPK-DN mice, compared to the WT (Fig. 4 E-F and I-J). AMPK is well known to stimulate the 
transcription of PGC-1 $\alpha$, resulting in mitochondrial biogenesis; ${ }^{31}$ therefore the effect of AMPK-DN on PGC-1 $\alpha$ was determined. Although PGC-1 $\alpha$ expression was increased due to the overload, the response was not different between the genotypes (Fig. 4A-B).

\section{The insulin signalling pathway is unaffected by the AMPK-DN}

The in vivo variation in glucose uptake between the genotypes may be due to the difference in the activation of the insulin signal; therefore, the total-Akt, phospho-Akt and TBC1D4 levels were determined. The overload resulted in significant increase in the t-Akt, p-Akt $\mathrm{Thr}^{308}$, and $\mathrm{p}$-Akt $\mathrm{Ser}^{473}$ levels; however, there were no interactions between the overload and genotypes (Fig. 5A-F). There was a significant increase in the p-Akt $\mathrm{Thr}^{308}$ levels in the AMPK-DN mice compared to the WT mice (Fig. 5C). Although the t-TBC1D4 level was significantly increased, the level of p-TBC1D4 at Ser ${ }^{595}$ was significantly reduced due to the overload (Fig. 6A and C). The delta change in the levels of t-TBC1D4 and p-TBC1D4 Ser $^{595}$ showed no difference between the genotypes (Fig. 6B and D). The level of p-TBC1D4 at $\mathrm{Thr}^{649}$ was unaffected both by the overload as well as the genotypes (Fig. 6E-F).

\section{No effect of AMPK-DN on upstream regulators of glycogen}

To elucidate the mechanism of muscle glycogen regulation in AMPK-DN due to overload, the upstream regulators of glycogen synthesis, total and phospho-GSK-3 $\beta$ and GS level were determined. Both the total and phospho-GSK-3 $\beta$ levels were increased due to overload but not regulated by the genotypes (Fig. 7A-D). The total and 
phospho-GS levels were unaffected both by the overload as well as genotypes (Fig. 7EH).

\section{Discussion}

The current study investigates whether AMPK is necessary for overload-induced glucose uptake in the skeletal muscles and inducing hypertrophy. It revealed that AMPK activation is dispensable for inducing hypertrophy but indispensable for glucose uptake and glycogenesis when subjected to functional overload.

Previous studies have reported skeletal muscle hypertrophy in the whole-body AMPK $\alpha 1 \mathrm{KO}$ mice compared to the WT mice. ${ }^{21}$ It reported the mass of the plantaris muscle in the AMPKa1 KO mice at rest to decrease such that the delta increase in muscle mass due to overload was higher than that of the WT mice. However, there was no significant difference in the muscle mass after the 7- and 21-day overload between the AMPK $\alpha 1 \mathrm{KO}$ and WT mice. ${ }^{21}$ The current study did not observe any difference in the plantaris muscle mass and the muscle mass gain after 14 days of overload between the WT and AMPK-DN mice; although the AMPK-DN mice showed lower AMPK $\alpha 1$ and $\alpha 2$ activities. ${ }^{30}$ This current result is in concert with the previous report that AMPK $\gamma 3 \mathrm{KO}$ did not affect the 14-day overload-induced plantaris muscle hypertrophy. ${ }^{6}$ Moreover, no difference was evident in the tibialis anterior muscle mass between the WT and inducible muscle of the AMPK $\alpha 1 / \alpha 2 \mathrm{KO}$ mice. ${ }^{10}$ Similarly, the plantaris muscle mass did not alter upon the knockout of either AMPK $\beta 1 / \beta 2$ or LKB1. ${ }^{22,32}$ In 
another study, Lantier et al. showed that AMPKa1/a2 KO on slow fibre, soleus muscle produce larger muscle mass. ${ }^{20}$ On the contrary, reports of O'Neill et al. and our previous study indicated that neither AMPK $\beta 1 / \beta 2$ nor AMPK-DN exhibited the difference in the mass of the soleus muscle. ${ }^{30,32}$ The previous studies assessing the effect of AMPK on muscle mass have used different types of genetic modifications on AMPK, accounting for the inconsistencies. This study indicated that AMPK-DN did not affect the plantaris muscle mass or the gain of mass after 14-day overload. Interestingly, the AMPK-DN mice demonstrated an accelerated slow fibre type shifting due to overload, although there was no difference in the composition of this fibre type at rest. Based upon these results, the function of AMPK on overload-induced muscle growth may differ depending upon the composition of the type of fibres.

Skeletal muscle glucose uptake and glycogen content were increased by 14 days of overload. Previous studies have demonstrated that 5- and 14-day overload-induced increase in muscle glucose uptake and glycogen contents in the plantaris muscles. ${ }^{6,7}$ The reports of Riedl et al. and that of the present study indicated an activation of the AMPK pathway after 14 days of overload, ${ }^{6}$ however, no previous study investigated whether AMPK activation regulates overload-induced glucose uptake and glycogenesis. This study has for the first time, identified that overload-induced glucose uptake and glycogenesis are lowered by the AMPK-DN. Therefore, AMPK activation is necessary for overload-induced glucose uptake and glycogenesis.

Skeletal muscles express GLUT1 that transport blood glucose into skeletal muscle, ${ }^{33}$ and GLUT4 that mediates exercise- and insulin-stimulated glucose uptake. ${ }^{34}$ 
AMPK activation is well known to increase the GLUT1 and GLUT4 expression. ${ }^{16,35,36}$ However, the chronic aerobic training-induced GLUT4 protein expression was not altered in the muscle-specific AMPK $\alpha 1 / \alpha 2 \mathrm{KO}$ mice. ${ }^{11}$ This study reported that the overload-induced increase in GLUT4 protein expression was lowered in the AMPK-DN mice, indicating an AMPK-dependent regulation of GLUT4 during overload. A previous study using genetic deletion of muscle GLUT4 indicated that GLUT4 is not necessary for overload-induced glucose uptake. ${ }^{7}$ An important difference between these two studies is the duration of overload. McMillin et al. has used 5-day overload that is the muscle-growing period ${ }^{25}$ and found no change in GLUT4 expression during the overload. On the contrary, a 14-day overload saturates the muscle growth and increases the GLUT4 expression. Similarly, Larkin et al. indicated a dramatic increase in the GLUT4 expression due to a 120-day overload. ${ }^{37}$ Therefore, GLUT4 expression is enhanced by a long-term overloading. The 14-day overload-induced approximately $200 \%$ increase in glucose uptake, whereas the 4- and 5-day overload increased glucose uptake by $\sim 80 \%{ }^{7,8}$ Collectively, this leads to the speculation that GLUT4 might be important for the maximal adaptation to overload-induced glucose uptake, but not be during the under-growing period.

Despite no significant difference, a high GLUT4 expression was reported in the sham muscles of the AMPK-DN mice, similar to that observed in the conventional muscle-specific AMPK $\alpha 1 / \alpha 2 \mathrm{KO}$ mice. ${ }^{11}$ This phenomenon was not observed in the inducible muscle-specific AMPK $\alpha 1 / \alpha 2 \mathrm{KO}$ mice. Thus, this may be caused as secondary adaptations to the conventional AMPK mutation. If GLUT4 is the limiting 
factor for muscle glucose transport, the glucose uptake into the sham muscle of AMPK-DN mice should have depicted a high value. However, there was no significant difference between the WT and AMPK-DN mice. We speculate that the lowered GLUT1 expression by AMPK-DN compensated for the increased GLUT4 in the AMPK-DN mice.

HKII is another important glucose handling intermediate, which phosphorylates glucose to glucose-6-phosphate and may be a major rate-limiting factor for glucose uptake in the insulin- or exercise-stimulated state. ${ }^{38}$ Chronic aerobic training increases the HKII expression in the muscle and is impaired in the muscle-specific AMPK $\alpha 1 / \alpha 2 \mathrm{KO}$ mice. ${ }^{11}$ The present study depicted no significant increase in HKII in the WT mice after a 14-day overload however; there was a significant decrease in the delta overload in the AMPK-DN mice compared to that in the WT mice. Therefore, AMPK also regulates the overload-induced change in HKII, affecting the lower glucose uptake in the AMPK-DN mice.

GLUT4 and HKII are highly expressed in the slow-twitch fibres compared to the fast-twitch fibres; ${ }^{39,40}$ therefore, if the overload-induced oxidative fibre type shift was impaired in the AMPK-DN mice, the lower expression of GLUT4 and HKII should have been reported. On the contrary, an enhancement of oxidative fibre type shift was evident. Also, the non-insulin-stimulated muscle glucose uptake does not differ hugely between the different compositions of fibre-types. ${ }^{10}$ Thus, the regulation of glucose uptake, GLUT4, and HKII in AMPK-DN mice is found to be independent of the fibre-type shifting. 
The activation of insulin signal pathway promotes the glucose uptake by the skeletal muscles, independent of the intensity of GLUT4 expression. Riedl et al. indicated that overload increases Akt signal activation, but the response does not differ in the AMPK $\gamma 3 \mathrm{KO}$ mice. ${ }^{6}$ This study also suggested that both the WT and AMPK-DN mice showed increased total-Akt and phosphorylated-Akt, but with no interaction between overload and genotypes. Moreover, the phosphorylation of TBC1D4 did not affect Akt phosphorylation. Therefore, overload-induced Akt activation is independent of AMPK, and the Akt/TBC1D4 signal may not be critical for overload-induced glucose uptake. In contrast, overload-induced AMPK/TBC1D1 signal activation is impaired by an AMPK-DN. AMPK has been shown as a regulator of muscle glucose uptake and glycogenesis after acute aerobic exercise and muscle contraction. ${ }^{41}$ Thus, overload-induced glucose uptake and glycogenesis might partially result from a chronic activation of AMPK.

The skeletal muscle glycogen is formed from the glucose transported from the blood into the muscle; therefore, overload-induced glycogenesis may be impaired because of a smaller amount of glucose uptake. GS also regulates glycogenesis; however, neither overload nor AMPK-DN causes any changes in the total expression as well as in the phosphorylated form. A negative upstream regulator of GS, GSK-3 $\beta$ is inactivated by an overload-induced increase in phosphorylation at Ser ${ }^{9}$. However, there was no interaction between the overload and AMPK-DN, which indicates that GS signal activation, imparts no effect to lower glycogenesis in the AMPK-DN mice.

Therefore, to conclude, the loss of AMPK activation during overload causes a 
normal hypertrophic response, with an impaired adaptation for glucose uptake and glycogenesis. It substantiates that AMPK is necessary for functional muscle hypertrophy, which the coupling increases muscle mass with metabolic adaptations. Furthermore, it is now evident that AMPK likely regulates the overload-induced change in GLUT4 and HKII expression; therefore AMPK-DN impairs glucose uptake and glycogenesis in the skeletal muscles.

\section{Funding}

This work was supported by the Japan Society for the Promotion of Science, Grants-in-Aid for Scientific Research (no. 18J01392 and 19K20007 to K.K., no. 18H03148 and 19K22806 to T.E., no. 19K11520 to T.H.); 


\section{References}

1. Diabetes Prevention Program (DPP) Research Group. The Diabetes Prevention Program (DPP): description of lifestyle intervention. Diabetes Care. 2002;25(12):2165-2171.

2. Umpierre D, Ribeiro PA, Kramer CK, et al. Physical activity advice only or structured exercise training and association with HbA1c levels in type 2 diabetes: a systematic review and meta-analysis. JAMA. 2011;305(17):1790-1799.

3. Bacchi E, Negri C, Zanolin ME, et al. Metabolic effects of aerobic training and resistance training in type 2 diabetic subjects: a randomized controlled trial (the RAED2 study). Diabetes Care. 2012;35(4):676-682.

4. Holten MK, Zacho M, Gaster M, Juel C, Wojtaszewski JF, Dela F. Strength training increases insulin-mediated glucose uptake, GLUT4 content, and insulin signaling in skeletal muscle in patients with type 2 diabetes. Diabetes. 2004;53(2):294-305.

5. DeFronzo RA, Jacot E, Jequier E, Maeder E, Wahren J, Felber JP. The effect of insulin on the disposal of intravenous glucose. Results from indirect calorimetry and hepatic and femoral venous catheterization. Diabetes. 1981;30(12):1000-1007.

6. Riedl I, Osler ME, Björnholm M, et al. AMPK $\gamma 3$ is dispensable for skeletal muscle hypertrophy induced by functional overload. Am J Physiol Endocrinol Metab. 2016;310(6):E461-E472.

7. McMillin SL, Schmidt DL, Kahn BB, Witczak CA. GLUT4 Is Not Necessary for Overload-Induced Glucose Uptake or Hypertrophic Growth in Mouse Skeletal Muscle. Diabetes. 2017;66(6):1491-1500.

8. Augert G, Van de Werve G, Le Marchand-Brustel Y. Effect of work-induced hypertrophy on muscle glucose metabolism in lean and obese mice. Diabetologia. 1985;28(5):295-301. 
9. Winder WW, Hardie DG. AMP-activated protein kinase, a metabolic master switch: possible roles in type 2 diabetes. Am J Physiol. 1999;277(1):E1-E10.

10. Hingst JR, Kjøbsted R, Birk JB, et al. Inducible deletion of skeletal muscle AMPK $\alpha$ reveals that AMPK is required for nucleotide balance but dispensable for muscle glucose uptake and fat oxidation during exercise [published online ahead of print, 2020 Jun 3]. Mol Metab. 2020;40:101028.

11. Fentz J, Kjøbsted R, Kristensen CM, et al. AMPK $\alpha$ is essential for acute exercise-induced gene responses but not for exercise training-induced adaptations in mouse skeletal muscle. Am J Physiol Endocrinol Metab. 2015;309(11):E900-E914.

12. Dreyer HC, Fujita S, Cadenas JG, Chinkes DL, Volpi E, Rasmussen BB. Resistance exercise increases AMPK activity and reduces 4E-BP1 phosphorylation and protein synthesis in human skeletal muscle. J Physiol. 2006;576(Pt 2):613-624.

13. Wilkinson SB, Phillips SM, Atherton PJ, et al. Differential effects of resistance and endurance exercise in the fed state on signalling molecule phosphorylation and protein synthesis in human muscle. J Physiol. 2008;586(15):3701-3717.

14. Kido K, Sase K, Yokokawa T, Fujita S. Enhanced skeletal muscle insulin sensitivity after acute resistance-type exercise is upregulated by rapamycin-sensitive mTOR complex 1 inhibition. Sci Rep. 2020;10(1):8509.

15. Thomson DM, Herway ST, Fillmore N, et al. AMP-activated protein kinase phosphorylates transcription factors of the CREB family. J Appl Physiol (1985). 2008;104(2):429-438.

16. McGee SL, van Denderen BJ, Howlett KF, et al. AMP-activated protein kinase regulates GLUT4 transcription by phosphorylating histone deacetylase 5. Diabetes. 2008;57(4):860-867. 
17. Croymans DM, Paparisto E, Lee MM, et al. Resistance training improves indices of muscle insulin sensitivity and $\beta$-cell function in overweight/obese, sedentary young men. J Appl Physiol (1985). 2013;115(9):1245-1253.

18. Schwingshackl L, Missbach B, Dias S, König J, Hoffmann G. Impact of different training modalities on glycaemic control and blood lipids in patients with type 2 diabetes: a systematic review and network meta-analysis. Diabetologia. 2014;57(9):1789-1797.

19. Bolster DR, Crozier SJ, Kimball SR, Jefferson LS. AMP-activated protein kinase suppresses protein synthesis in rat skeletal muscle through down-regulated mammalian target of rapamycin (mTOR) signaling. $J$ Biol Chem. 2002;277(27):23977-23980.

20. Lantier L, Mounier R, Leclerc J, Pende M, Foretz M, Viollet B. Coordinated maintenance of muscle cell size control by AMP-activated protein kinase. FASEB J. 2010;24(9):3555-3561.

21. Mounier R, Lantier L, Leclerc J, et al. Important role for AMPKalpha1 in limiting skeletal muscle cell hypertrophy. FASEB J. 2009;23(7):2264-2273.

22. McGee SL, Mustard KJ, Hardie DG, Baar K. Normal hypertrophy accompanied by phosphoryation and activation of AMP-activated protein kinase alphal following overload in LKB1 knockout mice. J Physiol. 2008;586(6):1731-1741.

23. Miura S, Kai Y, Kamei Y, et al. Alpha2-AMPK activity is not essential for an increase in fatty acid oxidation during low-intensity exercise. Am J Physiol Endocrinol Metab. 2009;296(1):E47-E55.

24. Baldwin KM, Valdez V, Schrader LF, Herrick RE. Effect of functional overload on substrate oxidation capacity of skeletal muscle. J Appl Physiol Respir Environ Exerc Physiol. 1981;50(6):1272-1276. 
25. Bodine SC, Baar K. Analysis of skeletal muscle hypertrophy in models of increased loading. Methods Mol Biol. 2012;798:213-229.

26. Toyoda T, Hayashi T, Miyamoto L, et al. Possible involvement of the alpha1 isoform of 5'AMP-activated protein kinase in oxidative stress-stimulated glucose transport in skeletal muscle. Am J Physiol Endocrinol Metab. 2004;287(1):E166-E173.

27. Kjøbsted R, Munk-Hansen N, Birk JB, et al. Enhanced Muscle Insulin Sensitivity After Contraction/Exercise Is Mediated by AMPK. Diabetes. 2017;66(3):598-612.

28. Nakano M, Hamada T, Hayashi $T$, et al. $\alpha 2$ isoform-specific activation of 5'adenosine monophosphate-activated protein kinase by 5-aminoimidazole-4-carboxamide-1- $\beta$-D-ribonucleoside at a physiological level activates glucose transport and increases glucose transporter 4 in mouse skeletal muscle. Metabolism. 2006;55(3):300-308.

29. Egawa T, Ohno Y, Goto A, Yokoyama S, Hayashi T, Goto K. AMPK Mediates Muscle Mass Change But Not the Transition of Myosin Heavy Chain Isoforms during Unloading and Reloading of Skeletal Muscles in Mice. Int J Mol Sci. 2018;19(10):2954.

30. Egawa T, Goto A, Ohno Y, et al. Involvement of AMPK in regulating slow-twitch muscle atrophy during hindlimb unloading in mice. Am J Physiol Endocrinol Metab. 2015;309(7):E651-E662.

31. Jäger S, Handschin C, St-Pierre J, Spiegelman BM. AMP-activated protein kinase (AMPK) action in skeletal muscle via direct phosphorylation of PGC-1alpha. Proc Natl Acad Sci U S A. 2007;104(29):12017-12022.

32. O'Neill HM, Maarbjerg SJ, Crane JD, et al. AMP-activated protein kinase (AMPK) beta1beta 2 muscle null mice reveal an essential role for AMPK in maintaining mitochondrial content and glucose uptake during exercise. Proc Natl Acad Sci U S A. 2011;108(38):16092-16097. 
33. Al-Khalili L, Chibalin AV, Kannisto K, et al. Insulin action in cultured human skeletal muscle cells during differentiation: assessment of cell surface GLUT4 and GLUT1 content. Cell Mol Life Sci. 2003;60(5):991-998.

34. Ryder JW, Kawano Y, Galuska D, et al. Postexercise glucose uptake and glycogen synthesis in skeletal muscle from GLUT4-deficient mice. FASEB J. 1999;13(15):2246-2256.

35. Zheng D, MacLean PS, Pohnert SC, et al. Regulation of muscle GLUT-4 transcription by AMP-activated protein kinase.J Appl Physiol (1985). 2001;91(3):1073-1083.

36. Fryer LG, Foufelle F, Barnes K, Baldwin SA, Woods A, Carling D. Characterization of the role of the AMP-activated protein kinase in the stimulation of glucose transport in skeletal muscle cells. Biochem J. 2002;363(Pt 1):167-174.

37. Larkin LM, Kuzon WM Jr, Halter JB. Synergist muscle ablation and recovery from nerve-repair grafting: contractile and metabolic function. J Appl Physiol (1985). 2000;89(4):1469-1476.

38. Fueger PT, Hess HS, Posey KA, et al. Control of exercise-stimulated muscle glucose uptake by GLUT4 is dependent on glucose phosphorylation capacity in the conscious mouse. J Biol Chem. 2004;279(49):50956-50961.

39. Megeney LA, Neufer PD, Dohm GL, et al. Effects of muscle activity and fiber composition on glucose transport and GLUT-4. Am J Physiol. 1993;264(4 Pt 1):E583-E593.

40. Kong X, Manchester J, Salmons S, Lawrence JC Jr. Glucose transporters in single skeletal muscle fibers. Relationship to hexokinase and regulation by contractile activity. J Biol Chem. 1994;269(17):12963-12967. 
41. Kjøbsted R, Roll JLW, Jørgensen NO, et al. AMPK and TBC1D1 Regulate Muscle Glucose Uptake After, but Not During, Exercise and Contraction. Diabetes. 2019;68(7):1427-1440. 


\section{Figures legends}

Fig. 1: AMPK pathway activation by the functional overload:

(A) Total AMPKa, (B) total ACC, (C) ACC Ser ${ }^{79}$ phosphorylation, (D) Total TBC1D1, and (E) TBC1D1 Ser ${ }^{231}$ phosphorylation in response to a two-week overload ( $\mathrm{n}=5$ for the $\mathrm{WT}$ and $\mathrm{n}=7$ for the AMPK-DN). Values are expressed as mean $\pm \mathrm{SEM}$.

$* * * * p<0.0001, * * * P<0.001$, and $* * P<0.01$ vs. the sham within each genotype; \#\#\#\# $p<0.0001, \# \#$ $\quad<0.001, \# \# p<0.01$, and \# $p<0.05$ vs. the wild-type within each condition. The line indicates the main effect.

Fig. 2: Changes in the skeletal muscle morphology:

(A) Bodyweight, (B) The plantaris muscle wet-weight, and (C) Gain of the plantaris muscle mass by overload ( $n=12$ for the WT and $n=14$ for the AMPK-DN). (D) MHC type I, (E) MHC type IIa/x, and (F) MHC type IIb pre-total MHC (n = 5 for the WT and $\mathrm{n}=7$ for the AMPK-DN). Values are expressed as mean \pm SEM. $* * * * p<0.0001$ and *** $P<0.001$ vs. the sham within each genotype; \# $p<0.05$ vs. the wild-type within each condition. The line indicates the main effect.

Fig. 3: The glucose uptake and glycogen content in the skeletal muscles due to the overload:

(A) Blood glucose ( $\mathrm{n}=5$ for the WT and $\mathrm{n}=7$ for the AMPK-DN). (B) The in-vivo plantaris muscle glucose uptake and (C) Delta overload glucose uptake by the plantaris muscle ( $\mathrm{n}=7$ for the WT and $\mathrm{n}=6$ for the AMPK-DN). (D) The glycogen content of 
the plantaris muscle and (E) The gain of glycogen of the plantaris muscle due to the overload ( $\mathrm{n}=7$ for the WT and $\mathrm{n}=7$ for the AMPK-DN). The values are expressed as mean \pm SEM. $* * * * p<0.0001$ and $* * P<0.01$ vs. the sham within each genotype; \#\# $p$ $<0.01$ and \# $p<0.05$ vs. the wild-type within each condition.

Fig. 4: The overload-induced change in the expression of glucose handling intermediates:

(A) PGC-1 $\alpha$, (B) Delta overload PGC-1 $\alpha$, (C) HKI, (D) Delta overload HKI, (E) HKII, (F) Delta overload HKII, (G) GLUT1, (H) Delta overload GLUT1, (I) GLUT4, and (J) Delta overload GLUT4 ( $\mathrm{n}=5$ for the WT and $\mathrm{n}=7$ for the AMPK-DN). The values are expressed as mean \pm SEM. $* * * * p<0.0001, * * * p<0.001$, $* * P<0.01$, and $* P<0.05$ vs. the sham within each genotype; \# $p<0.05$ vs. the wild-type within each condition. The line indicates the main effect.

Fig. 5: The effect of overload and genotype on the Akt expression:

(A) Total-Akt, (B) Delta total-Akt, (C) Akt phosphorylation at $\mathrm{Thr}^{308}$, (D) Delta overload Akt phosphorylation at $\mathrm{Thr}^{308}$, (E) Akt phosphorylation at $\mathrm{Ser}^{473}$, and (F) delta overload Akt phosphorylation at $\operatorname{Ser}^{473}$ ( $\mathrm{n}=5$ for the WT and $\mathrm{n}=7$ for the AMPK-DN). The values are represented as mean \pm SEM. $* * * * p<0.0001$ and $* * p<0.01$ vs. the sham within each genotype. The line indicates main effect.

Fig. 6: Change in the total and phospho-TBC1D4 due to overload and genotype: 
(A) The total-TBC1D4, (B) Delta total-TBC1D4, (C) TBC1D4 phosphorylation at Ser ${ }^{595}$, (D) Delta overload TBC1D4 phosphorylation at $\mathrm{Ser}^{595}$, (E) TBC1D4 phosphorylation at $\mathrm{Thr}^{649}$, and (F) Delta overload TBC1D4 phosphorylation at $\mathrm{Thr}^{649}$ (n $=5$ for the $\mathrm{WT}$ and $\mathrm{n}=7$ for the AMPK-DN). The values are represented as mean \pm SEM. $* * * * p<0.0001$ and $* p<0.05$ vs. the sham within each genotype. The line indicates the main effect.

Fig. 7: The activation of glycogen synthase signalling due to the overload:

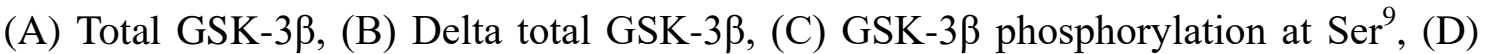
delta overload GSK-3 $\beta$ phosphorylation at Ser $^{9}$, (E) Total GS, (F) Delta overload total GS, (G) GS phosphorylation at $\operatorname{Ser}^{641}$, and (H) Delta overload total GS phosphorylation at $\operatorname{Ser}^{9}(n=5$ for the WT and $n=7$ for the AMPK-DN). The values are represented as mean \pm SEM. $* * * p<0.001$ vs. the sham within each genotype. $\# p<0.05$ vs. the wild-type within each condition. The line indicates the main effect. 
京都大学

KYOTO UNIVERSITYly weight

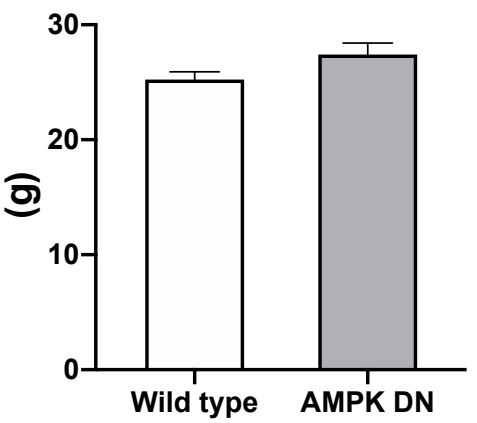

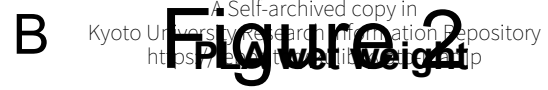

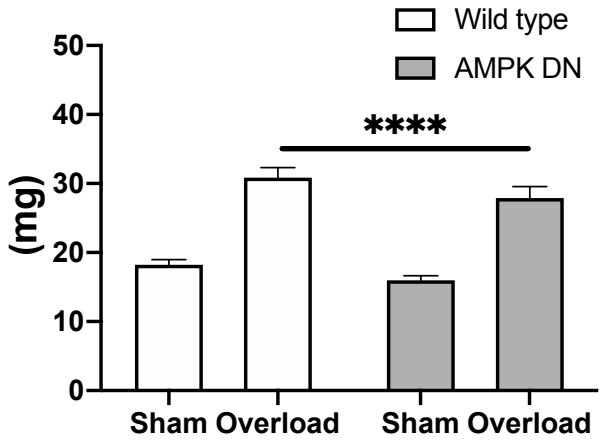

C PLA muscle

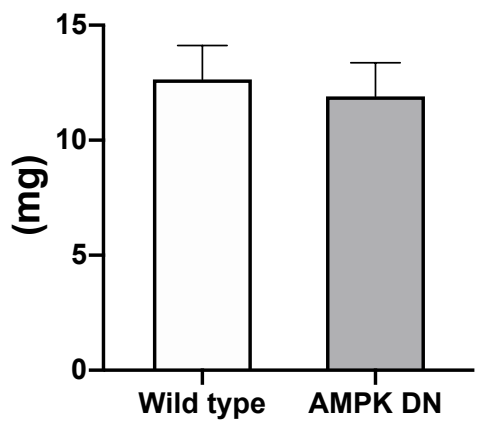

$D$

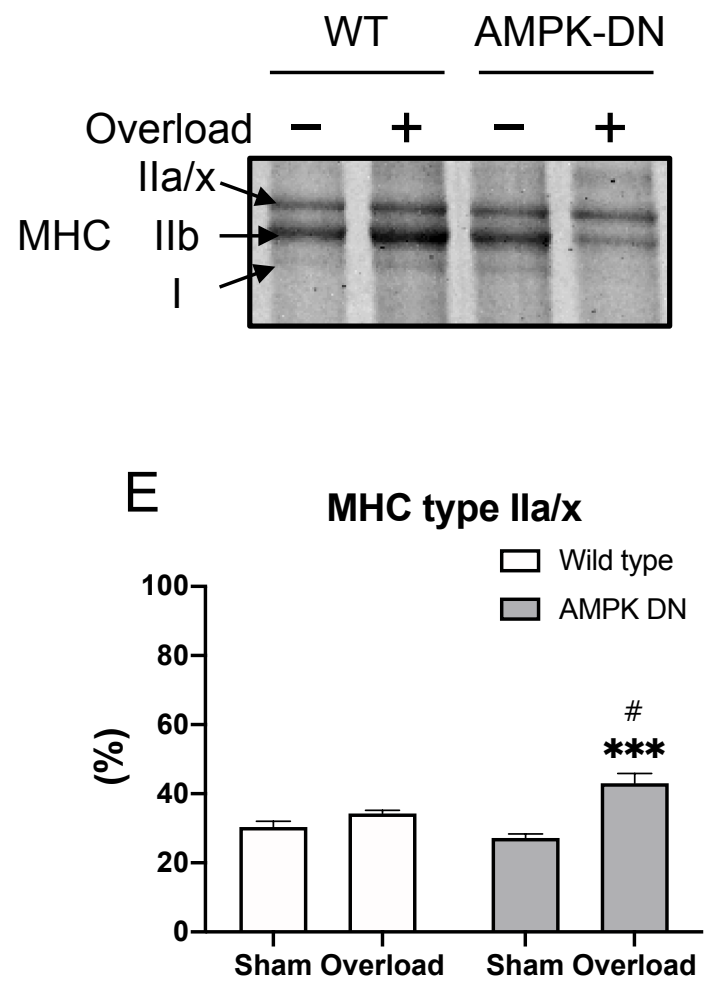

MHC type I

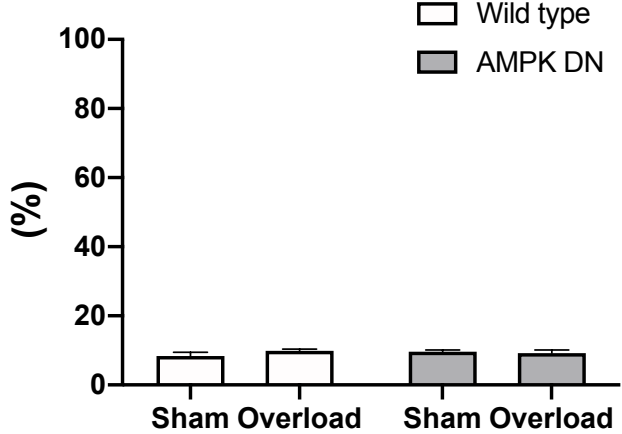

$F$

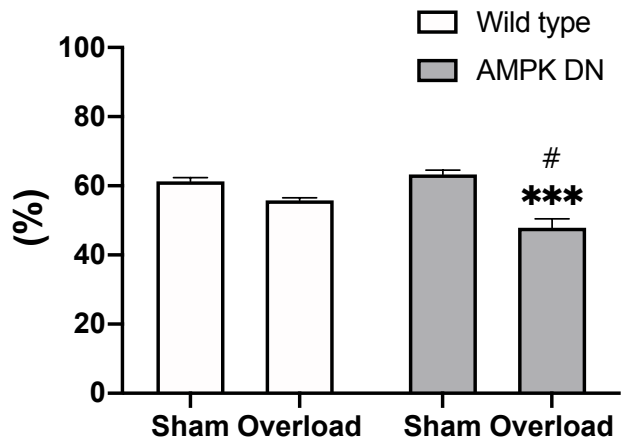



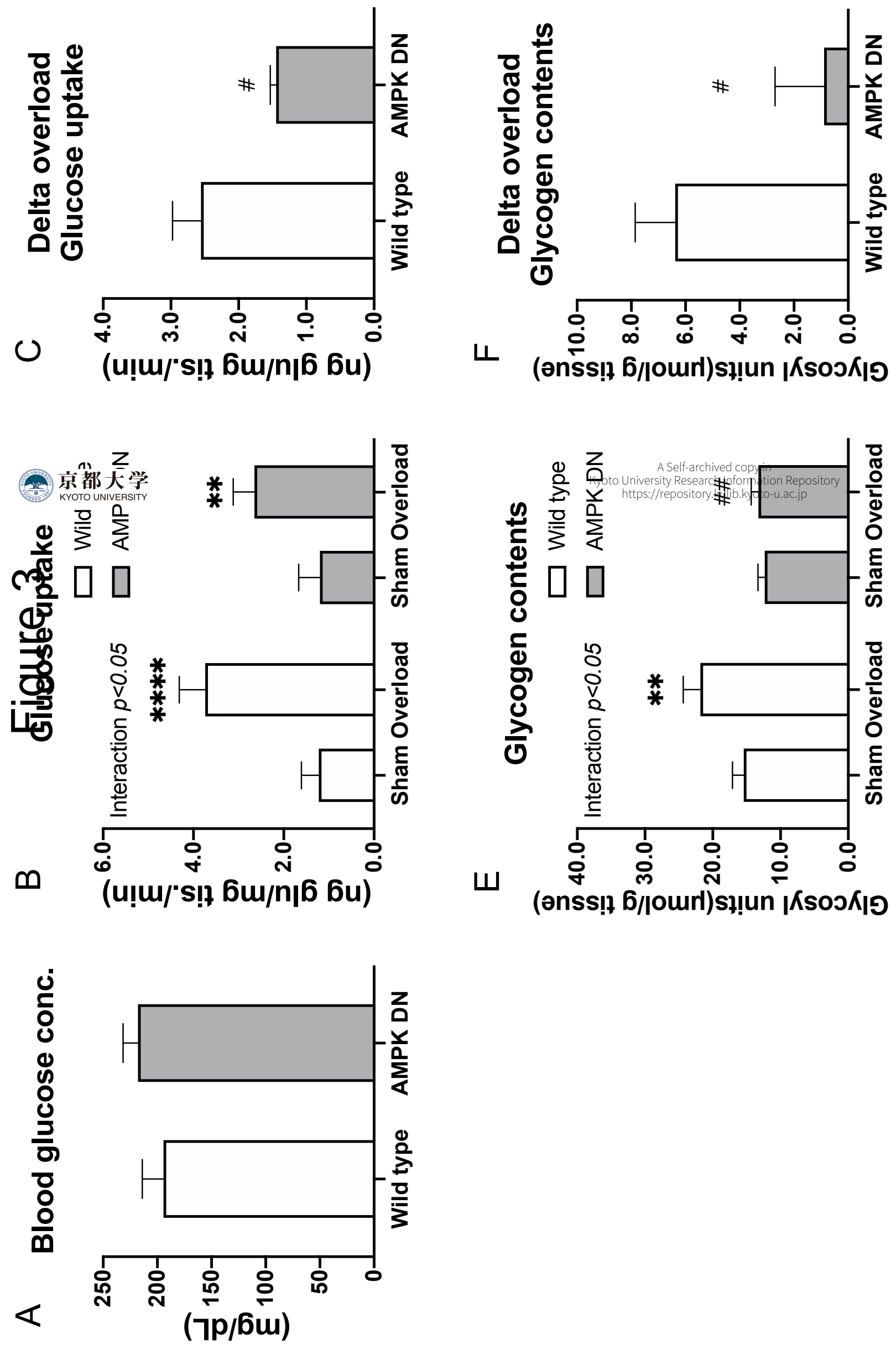

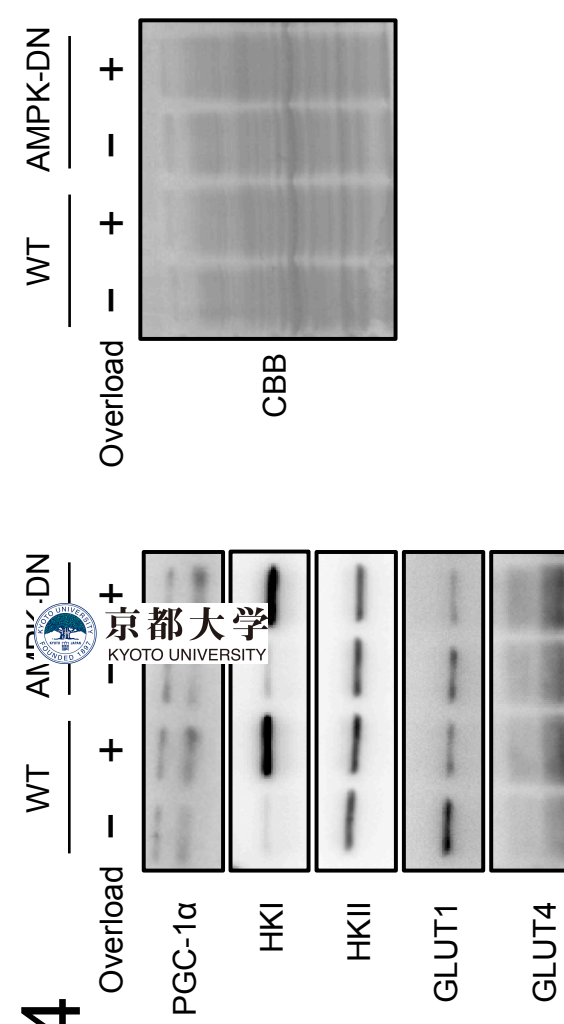

(1)
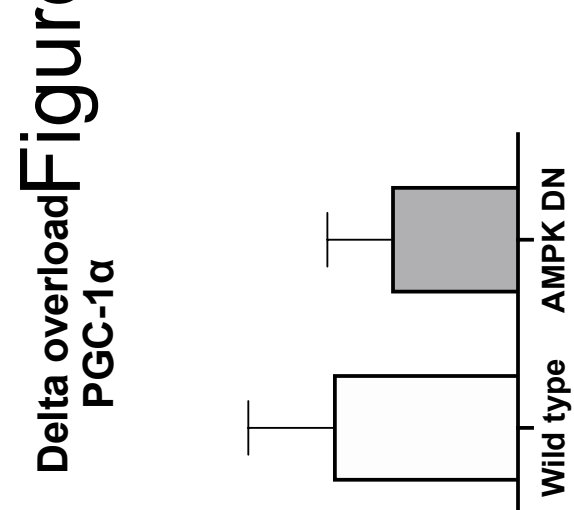

。

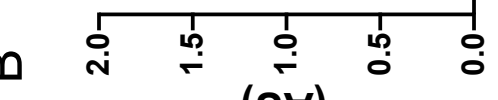
(n)

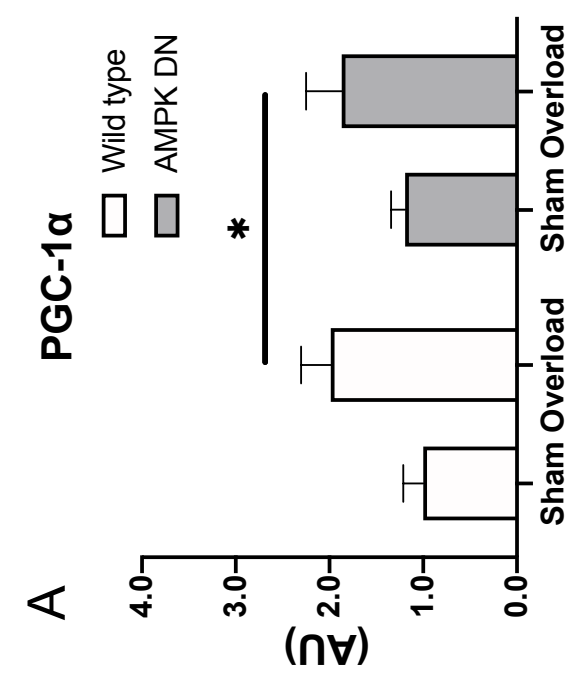

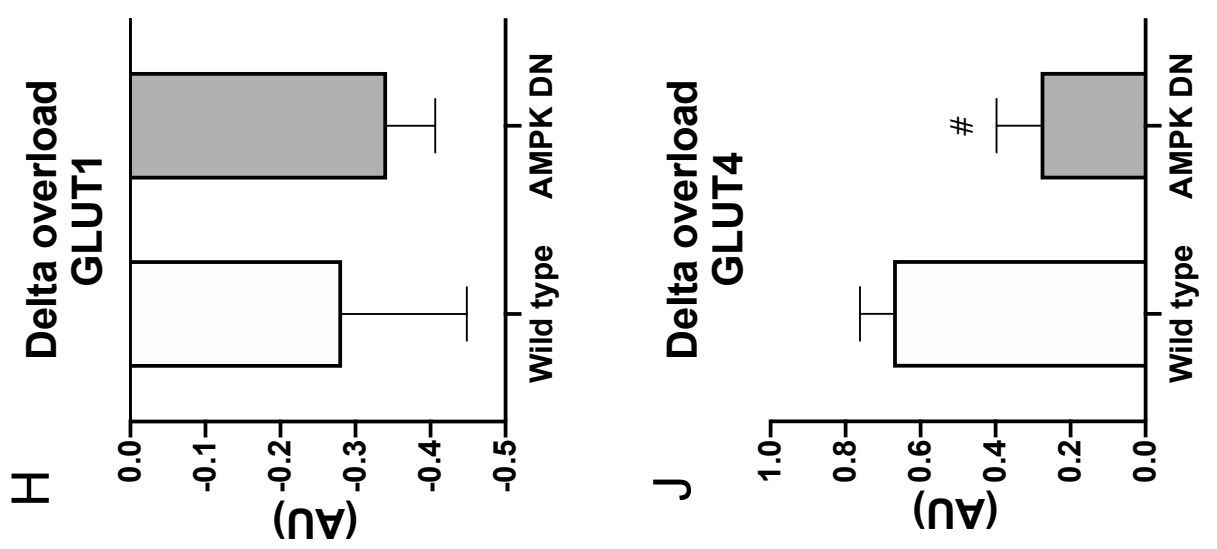
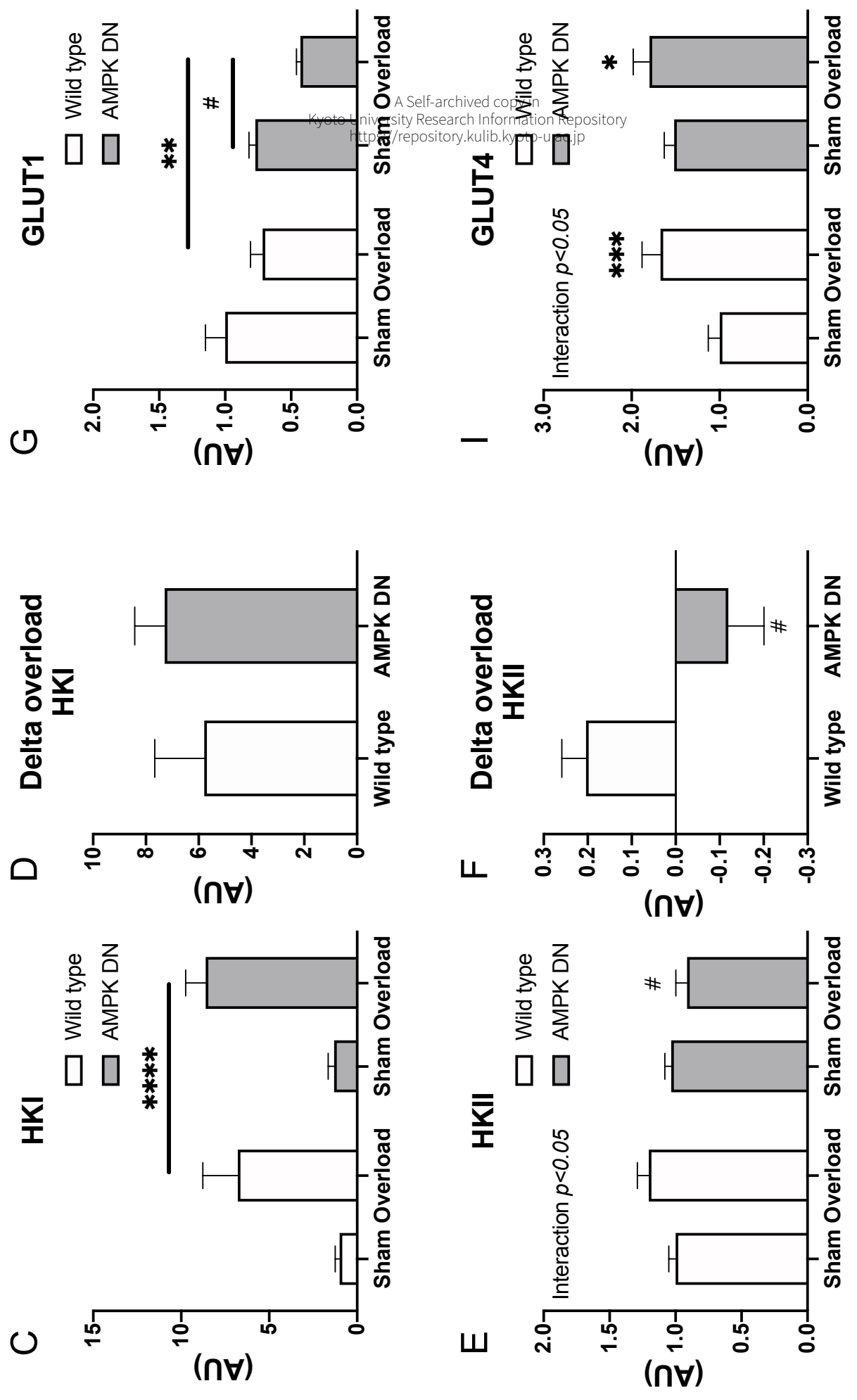

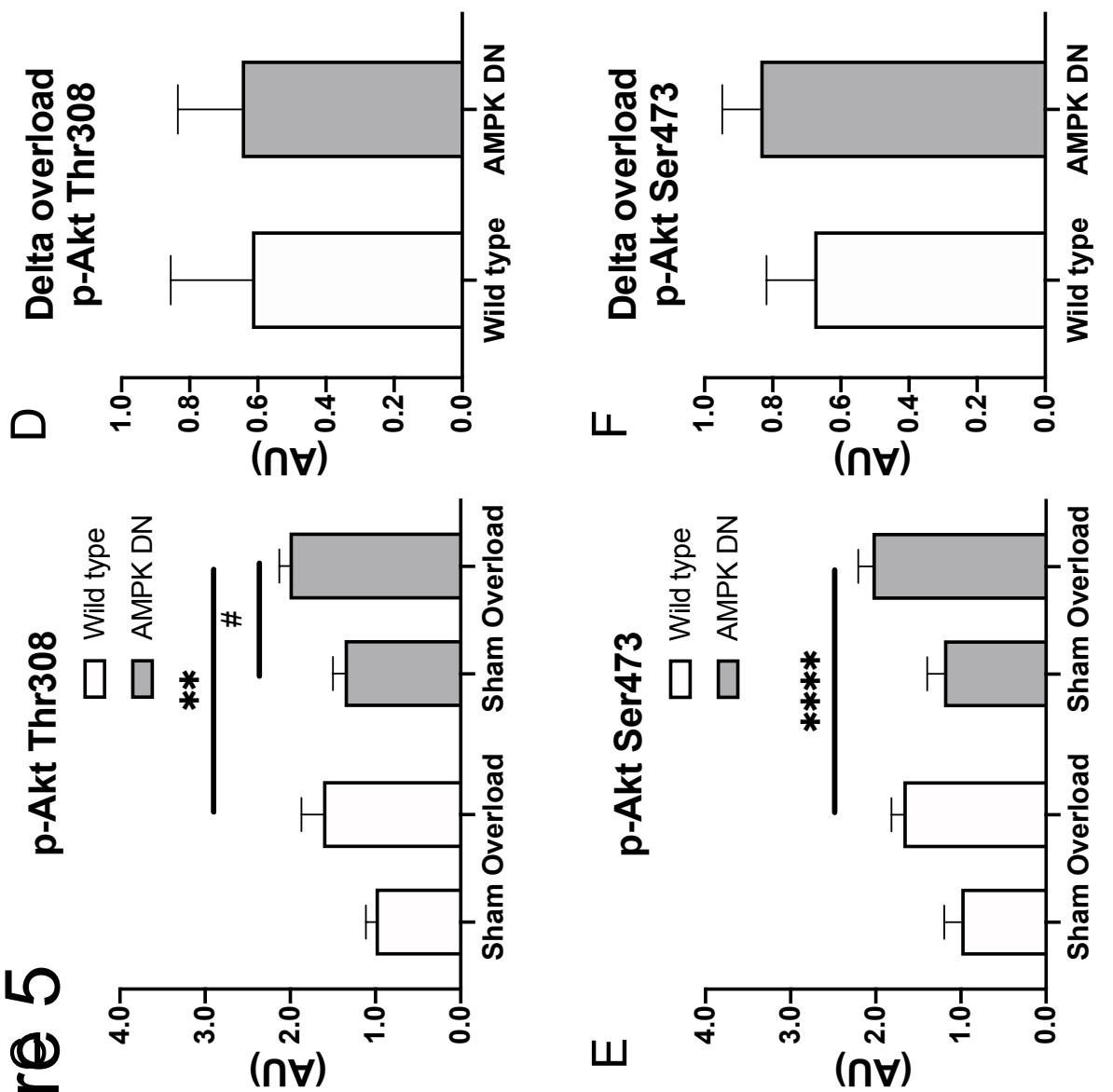

\section{$\overline{5}$}

京都大学
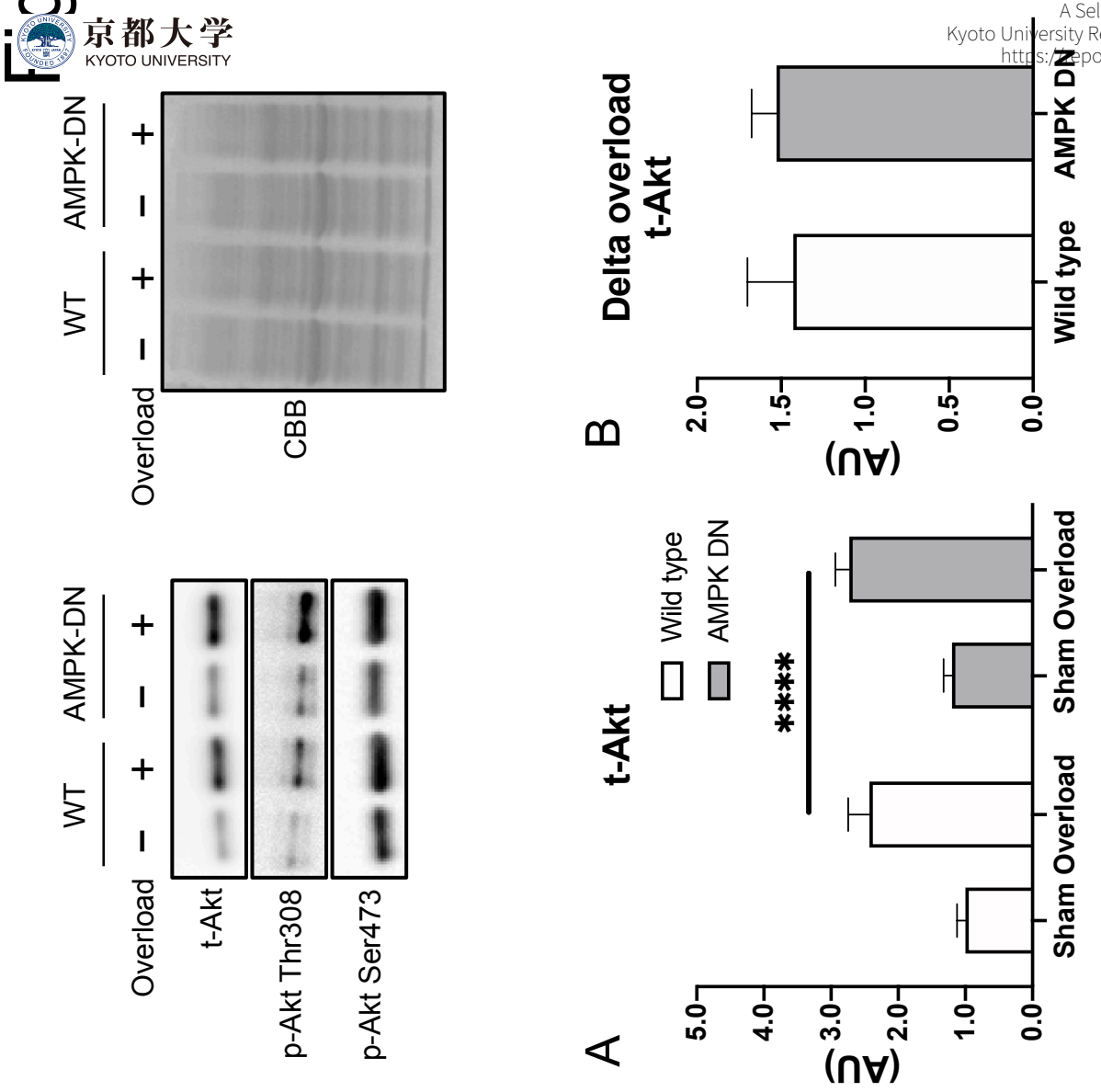

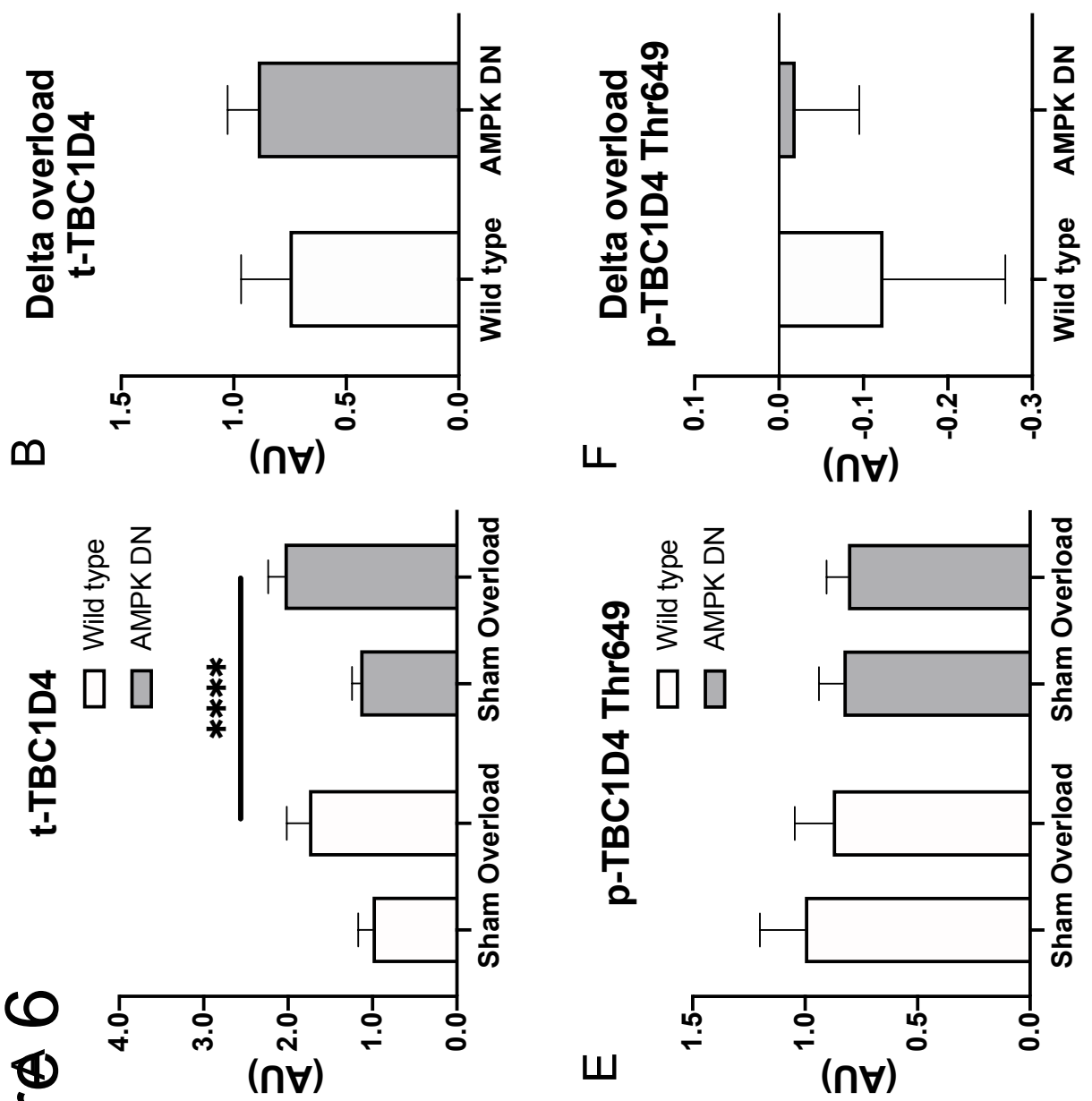

כ

공
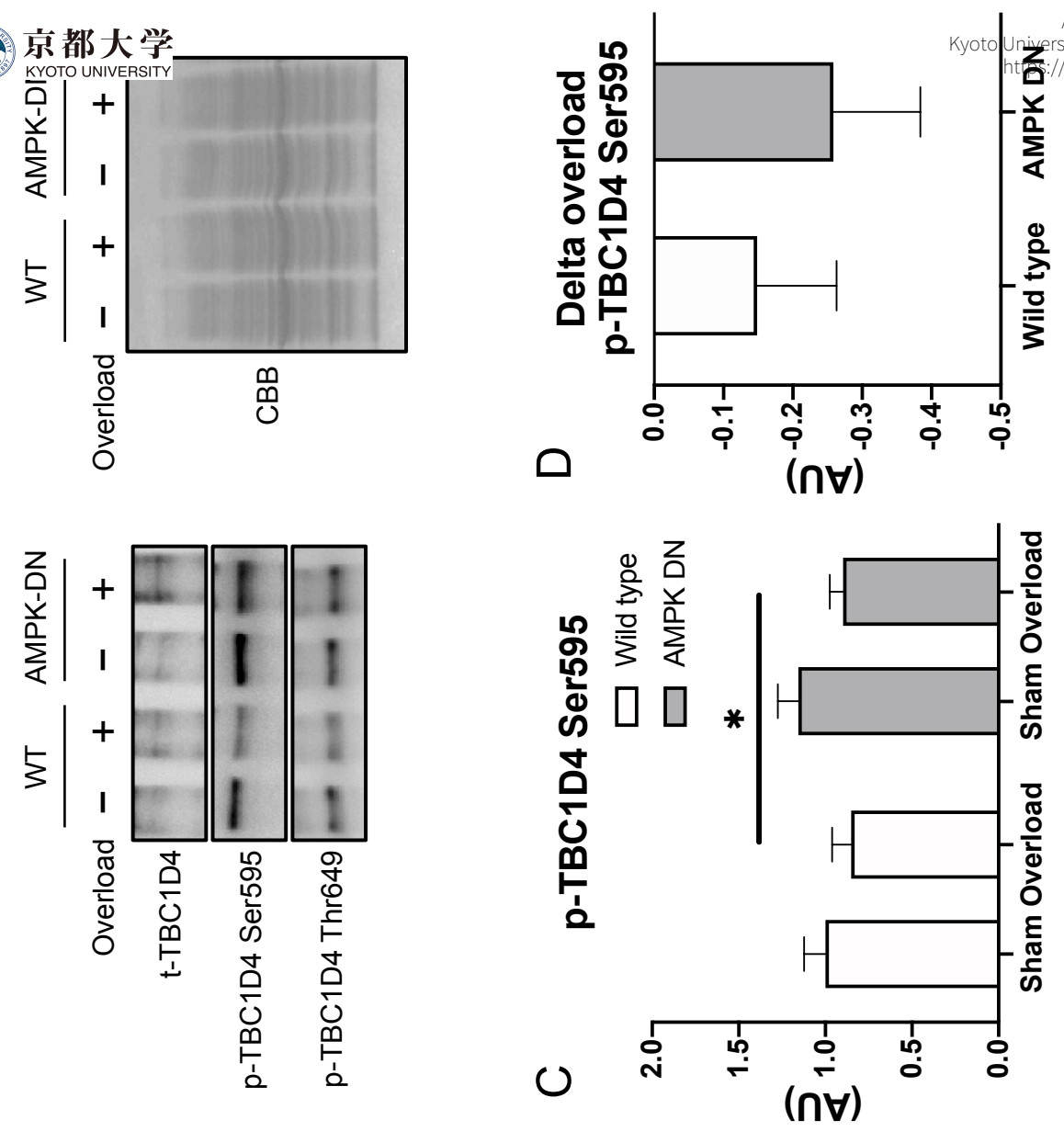
京都大学
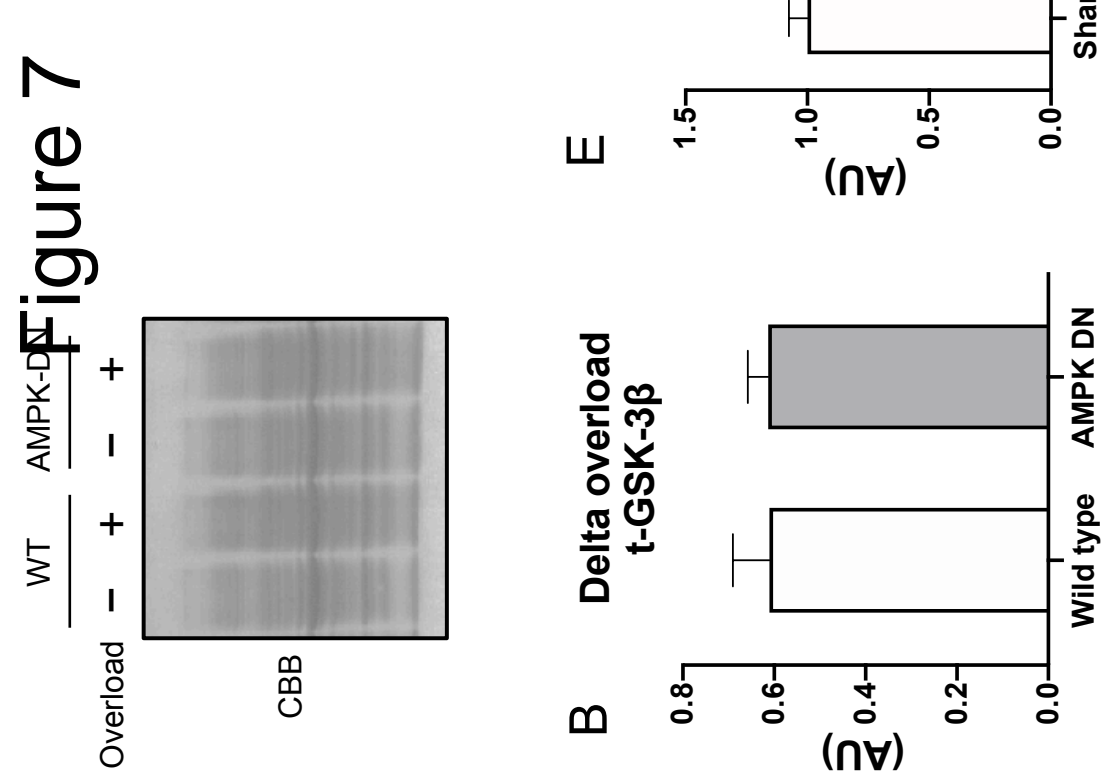

$z$
$z$
$z$
$z$
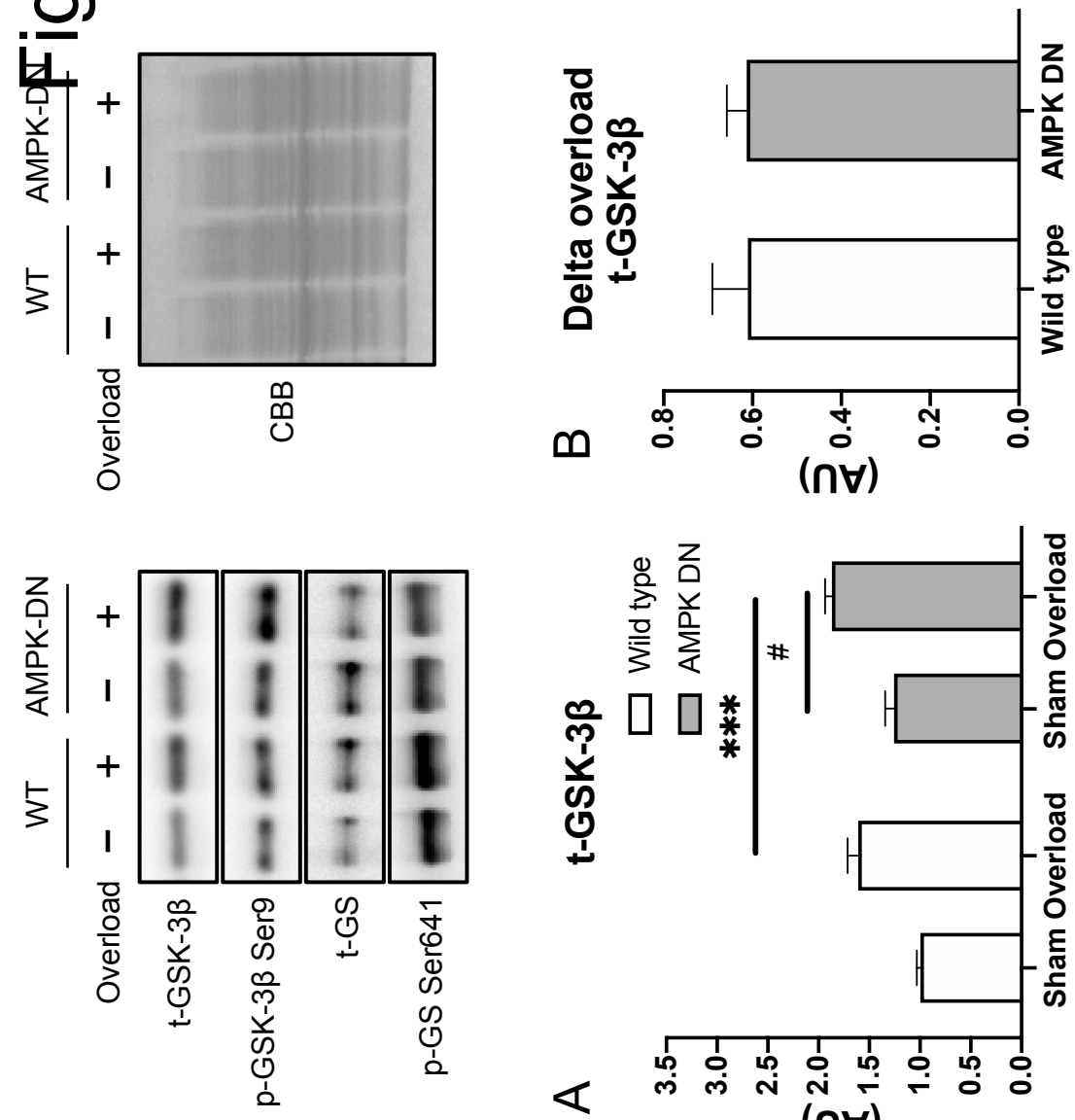
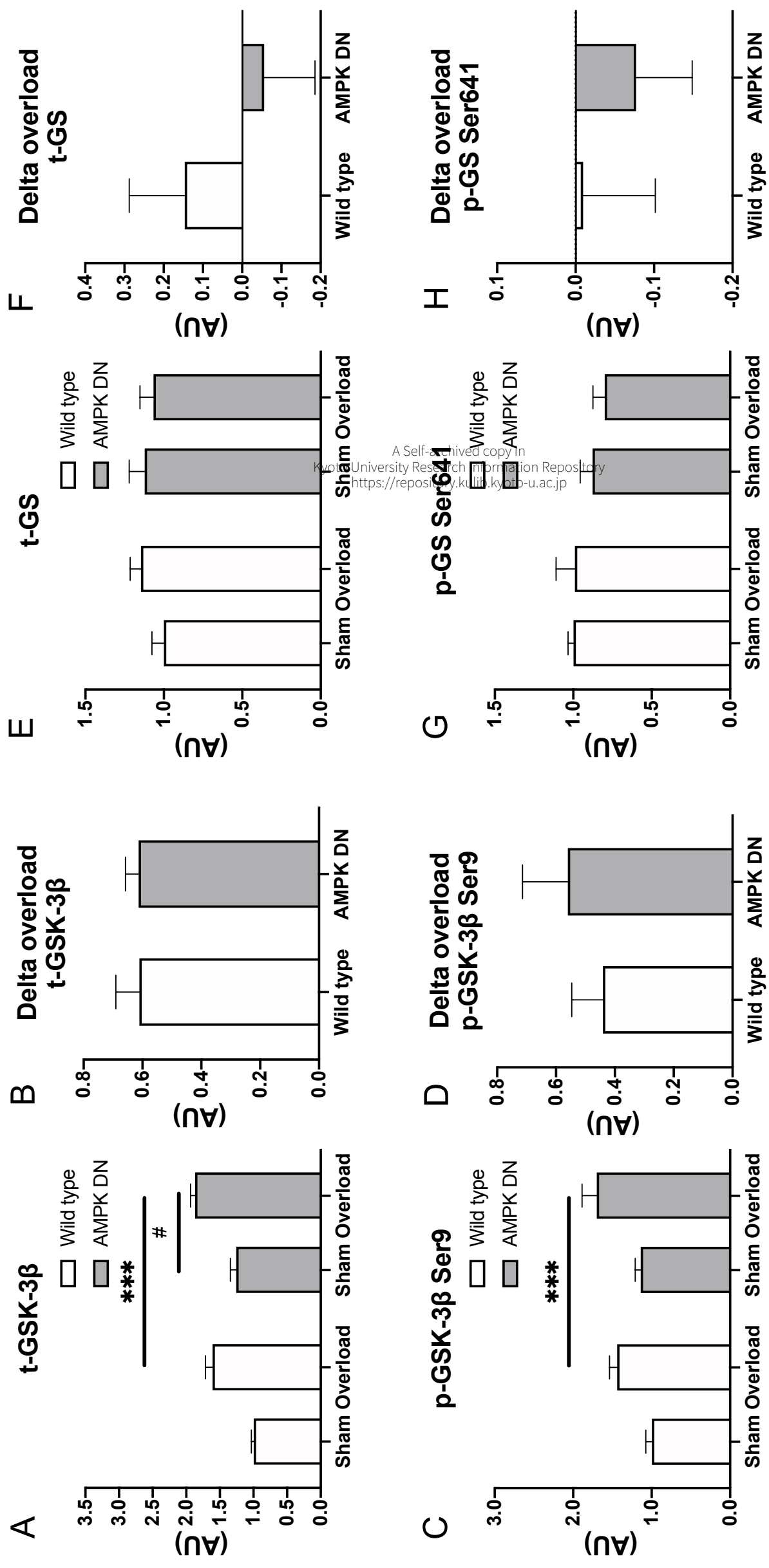